\title{
Adatom decorated shape-controlled metal nanoparticles: advanced electrocatalysts for energy conversion
}

\author{
Matheus B. C. de Souzaa ${ }^{\text {, Pablo S. Fernández }}{ }^{\mathrm{a}}$, J. Solla-Gullón ${ }^{\mathrm{b} *}$ \\ alnstitute of Chemistry, State University of Campinas, PO Box 6154, 13083-970, \\ Campinas SP, Brazil. \\ bInstituto de Electroquímica, Universidad de Alicante, Apdo. 99, E-03080 Alicante, \\ Spain \\ *Corresponding author: jose.solla@ua.es
}

\section{Summary}

The use of adatom decorated shape-controlled metal nanoparticles in electrocatalysis, and particularly for energy conversion reactions, has made important contributions to the development of better electrocatalysts. In this short review, we highlight some of the most relevant findings and discuss about future challenges.

Keywords: metal nanoparticles; shape-controlled; adatoms; Electrocatalysis.

\section{Introduction}

The development of new electrocatalysts for electrochemical energy conversion reactions is a question of paramount importance and has been the subject of innumerable studies. In this regard, the use of shape-controlled metal nanoparticles (SNPs) has produced a remarkable impact on this topic and their application is currently being explored in an increasing number of contributions $[1 \cdots-10]$. Therefore, it is now widely accepted that the shape of metal nanoparticles (NPs), i.e. the particular arrangement of the atoms at their surface, can be reasonably well-controlled. Consequently, as extensively shown with metal single crystal electrodes, their electrocatalytic properties can be optimized for the reactions of interest. However, it is very important to recall that even with very well-defined (in terms of size and shape) NPs, their surface structure will be much more complex than that of metal single crystals, including stepped and kinked surfaces. NPs contain not only some welloriented surface domains of different dimensions, but also a determined number of defects (corner, edge, step and kink sites), all of them contributing in a different extension (depending on the reaction under study), to the electrocatalytic activity. 
Additionally, although many options are now available for the synthesis of SNPs, only those methodologies able to produce SNPs with clean surfaces must be considered for electrocatalytic studies because this (surface cleaning) is a fundamental requirement to obtain reliable data and, in consequence, properly understand the surface structureelectrocatalytic reactivity relationships [11॰].

Unfortunately, despite SNPs have provided clear improvements in the electrocatalytic activity of different electrochemical energy conversion reactions, enhanced activities and stabilities are still required. Different strategies are being considered to achieve these goals including the preparation of alloyed, core-shell nanostructured, and surface decorated shape-controlled metal and metal alloy NPs. Only this latter topic will be cover in this review. Readers interested in the other approaches are referred to [12-20]. The selective surface decoration with adsorbed adatoms (foreign atoms) of metal materials, particularly well-defined surfaces but also NPs with a polyoriented surface structure (quasi-spherical NPs), have been widely applied with the aim of improving the reactivity and selectivity of many different reactions [21-27]. These enhanced properties have been mainly explained in terms of third-body, electronic and bifunctional effects. Third-body effects take place when the second element acts as a mere spectator, blocking surface sites and inhibiting an undesired reaction path. However, electronic effects occur when the modified surface also changes its electronic properties. Finally, bifunctional effects take place if the second metal also contributes to the reaction providing a required group at lower potentials, thus facilitating the reaction mechanism.

Although it is not possible to cover all up-to-date studies about this topic, this review highlights some relevant contributions which will be grouped in terms of improved activity, stability and modified selectivity. Figure 1 schematically illustrates the topic covered by this review. 


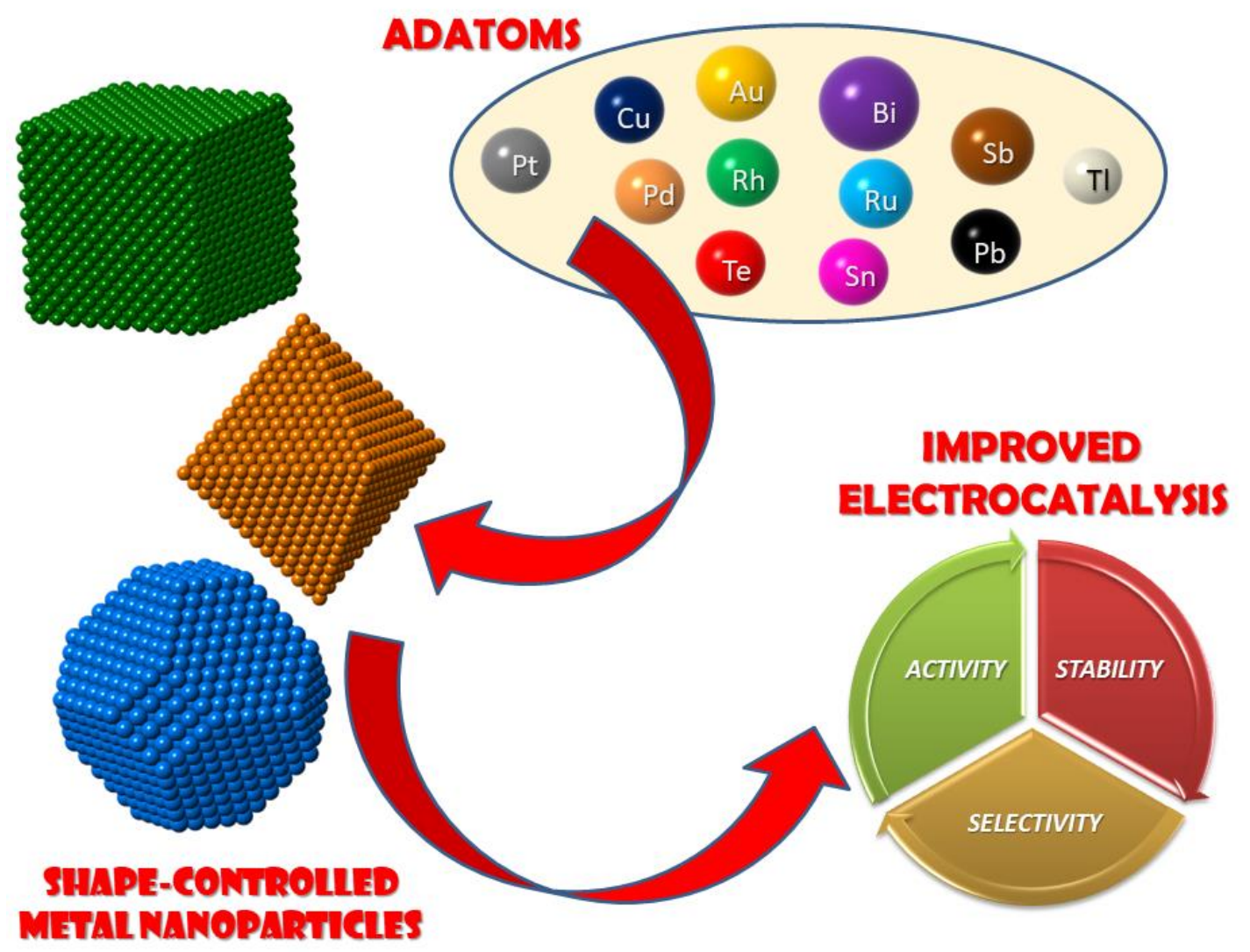

Figure 1. Schematically representation of the topic covered in this contribution.

\section{Enhanced electrocatalytic activity}

Feliu and coworkers published numerous contributions on the use of different adatoms to selectively decorate the surface of different SNPs towards formic acid electrooxidation. $\mathrm{Bi}$ [28*, 29], $\mathrm{Pd}$ [30, 31], Sb [32] and more recently $\mathrm{TI}$ [33] and $\mathrm{Pb}$ [34] have been used as surface modifiers. An improved electrocatalytic activity is obtained in all cases, although the enhancement factor strongly depends on the surface structure of the substrate and the nature and coverage of the adatom. Interestingly, independently of the adatom used, the so-called indirect pathway is always hindered (through a third body effect) and the reaction proceeds via the direct pathway. Additionally, in some particular systems such as $\mathrm{Bi}$ and $\mathrm{Sb}$ decorated octahedral $\mathrm{Pt}$ NPs, electronic effects are also observed.

Sun and co-workers also used a similar surface adatom decoration with high-index $\mathrm{Pt}$ NPs $\left[3^{\circ}, 36\right]$ as substrate. In particular, tetrahexahedral (THH) Pt NPs were decorated with $\mathrm{Bi}\left[3^{\circ}\right]$ or $\mathrm{Au}$ [36] and tested towards formic acid electrooxidation. The results indicated that the Au decoration provides enhanced activity in the low potential range 
due to the hindrance of the CO poison formation through the dehydration step (indirect pathway) by a third body effect. However, the Bi decorated THH Pt NPs displayed, at the highest $\mathrm{Bi}$ coverage $\left(\theta_{\mathrm{Bi}}\right.$ about 0.9 ), an enhancement factor of about 20 (in terms of peak current density) in comparison with the bare ones during voltammetric studies. Also, from chronoamperometric measurements, a very significant enhancement that varied from 65 to 1.5, depending on the electrode potential and $\mathrm{Bi}$ coverage, was obtained. Importantly, for the $\mathrm{Bi}$ decorated samples, the activity is more than five times higher than that of Au-modified $\mathrm{THH} \mathrm{Pt}$, thus indicating that both third-body and electronic effects are contributing to the enhanced activity.

Yang and Lee reported a very interesting approach dealing with the epitaxially deposition of Pt on gold octahedral NPs [37]. For formic acid electrooxidation, the electrocatalytic activity of the Pt decorated gold octahedra remarkably increased for decreasing $\mathrm{Pt}$ coverages, particularly in the submonolayer range. Thus, for a 0.05 monolayer of $\mathrm{Pt}$, a mass activity of about $63 \mathrm{~A} \mathrm{mgPt}^{-1}$ is found which is about 7,120 and 170 times higher than those obtained with 1 monolayer $(\mathrm{ML}), 5 \mathrm{ML}$ and with a commercial $\mathrm{Pt} / \mathrm{C}$ catalyst, respectively. This impressive enhancement was attributed not only to a third body effect but also to bifunctional effects from neighboring $\mathrm{Pt}-\mathrm{Au}$ sites (available bare Au sites are required).

For methanol electrooxidation, Sun and co-workers showed that Ru decorated $\mathrm{THH} P \mathrm{Pt}$ NPs present a high tolerance to $\mathrm{CO}$ poisoning and the onset potential shift to about 0,1 $\mathrm{V}$ towards more negative potentials [38]. In comparison with $\mathrm{Ru}$ decorated $\mathrm{Pt} / \mathrm{C}$ or with commercial PtRu alloy nanoparticle catalyst, these Ru modified THH Pt NPs display higher activity in the low potential range. As deduced from CO stripping experiments, the enhanced activity is attributed to a bifunctional mechanism.

Ethanol electrooxidation is also susceptible to be improved using adatom decorated SNPs. In this regard, Lin and co-workers used Bi decorated THH Pd NPs towards ethanol oxidation in alkaline medium [39]. The activity of the Bi decorated THH Pd NPs, at the optimum Bi coverage ( $\theta_{\mathrm{Bi}}$ about 0.7 ), was found to be 3 and 12 times higher than that obtained with the bare THH Pd NPs and a $\mathrm{Pd} / \mathrm{C}$, respectively. The enhanced activity was explained in terms of electronic effects.

More recently, Feliu and co-workers prepared different adatom modified ( $\mathrm{Sn}, \mathrm{Rh}, \mathrm{Ru}$ and $\mathrm{Pb}$ ) SNPs toward ethanol electrooxidation both in acidic and alkaline solutions [40]. In acidic medium, only Sn decorated shaped Pt NPs displayed slightly improved properties (onset oxidation potential shifted to negative values and reduced hysteresis). In addition, this enhanced activity was found to be dependent of the surface structure 
of the Pt NPs (although the activity was also affected by the Sn coverage, potential region and electrochemical method applied (cyclic voltammetry vs chronoamperometry)). In alkaline solution, where high activities are already found with the bare samples, none of the adsorbed adatoms used provided significant enhancements.

Cai and co-workers also reported that the electrocatalytic activity towards ethylene glycol oxidation in alkaline solution on $\mathrm{Pd}$ concave nanocubes can be enhanced through Bi surface decoration [41]. At the optimum Bi coverage ( $\theta_{\mathrm{Bi}}$ about 0.3 ), the activity of the $\mathrm{Bi}$ decorated samples was about 2.5 times higher than the bare ones. XPS measurements showed a change in electronic state of Pd by the Bi modification. In addition, ATR-SEIRAS measurements suggest that, in comparison with the bare surfaces, the presence of $\mathrm{Bi}$ adatoms promotes the cleavage of the $\mathrm{C}-\mathrm{C}$ bond.

Coutanceau and co-workers also showed that Bi decorated shape-controlled Pd NPs displayed enhanced activities towards glycerol electrooxidation in comparison with the unmodified ones [42,43*]. Higher activities were found with the Bi decorated cubic Pd NPs than with the octahedral ones.

To complete this section, it is worth mention that several and outstanding contributions have been reported on metal doped shape-controlled metal (including alloys and coreshell) nanoparticles towards oxygen reduction. However, to the best of our knowledge, the doping is always incorporated into the structure of the NPs and consequently, is out of the scope of this review. Readers interested in this topic are referred to Ref. 44-49.
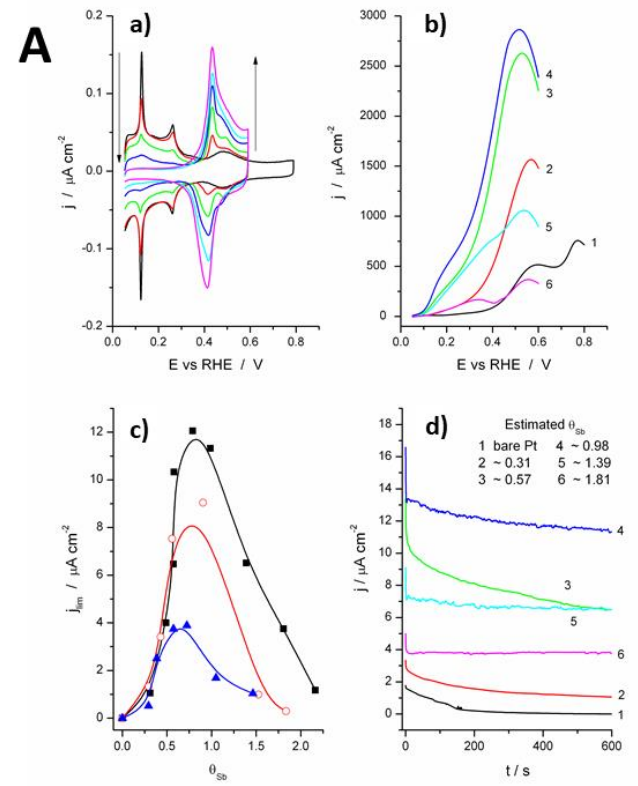

B
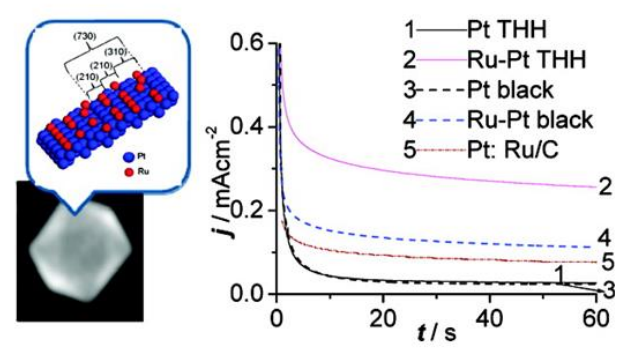

C

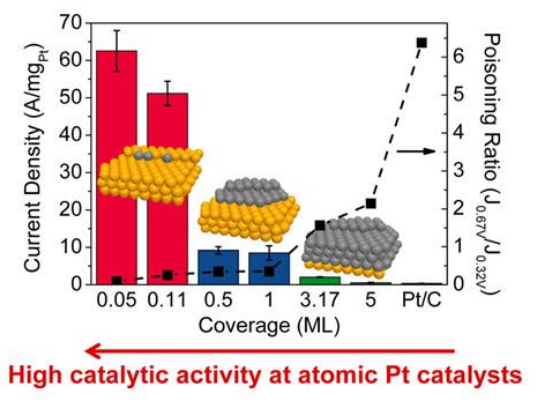


Figure 2. A) Voltammetric profiles for octahedral Pt nanoparticles decorated with increasing amounts of $\mathrm{Sb}$ in $0.5 \mathrm{M} \mathrm{H}_{2} \mathrm{SO}_{4}$ in the absence (a) and presence (b) of $0.1 \mathrm{M} \mathrm{HCOOH}$. Scan rate (a) $50 \mathrm{mVs}^{-1}$ and (b) $20 \mathrm{mVs}^{-1}$. c) Current densities after $10 \mathrm{~min}$ at $0.2 \mathrm{~V}$ for Sb/Ptoctahedral (solid squares), $\mathrm{Sb} / \mathrm{Pt}_{\text {spherical }}$ (open circles) and $\mathrm{Sb} / \mathrm{Pt}_{\text {cubic }}$ (solid triangles) nanoparticles. $\mathrm{d}$ ) Chronoamperometric curves recorded at $0.2 \mathrm{~V}$ with $\mathrm{Sb} / \mathrm{Pt}_{\text {coctahedral nanoparticles for increasing }}$ $\theta_{\text {sb }}$. Test solution $\mathrm{H}_{2} \mathrm{SO}_{4}(0.5 \mathrm{M})$ and $\mathrm{HCOOH}(1 \mathrm{M})$. Reproduced with permission from ref [32]. Copyright (2013) John Wiley and Sons. B) Chronoamperometric measurements recorded at $0.25 \mathrm{~V}$ in $1.0 \mathrm{M} \mathrm{CH}_{3} \mathrm{OH}+0.1 \mathrm{M} \mathrm{HClO}_{4}$ solution for Ru decorated ( $\theta_{\mathrm{Ru}}$ about 0.4 ) THH Pt NPs (solid line) in comparison with other relevant catalyst (Pt black (dashed line) and PtRu/C (dashed-dotted line)). Reprinted with permission from ref [38]. Copyright (2012) American Chemical Society. C) Mass activities and poisoning ratios (see ref [37] for details) obtained in $0.5 \mathrm{M} \mathrm{HCOOH}+0.1 \mathrm{M} \mathrm{H}_{2} \mathrm{SO}_{4}$ with Pt decorated gold octahedral NPs having different Pt coverages. A standard $\mathrm{Pt} / \mathrm{C}$ catalyst is also included for sake of comparison. Reprinted with permission from ref [37]. Copyright (2013) American Chemical Society.

\section{Improved electrocatalytic stability}

Adatom surface decoration is also an interesting approach to achieve improved stabilities. As shown by Kodama and co-workers, stepped Pt single crystals selectively decorated with $\mathrm{Au}$ adatoms at (100) step sites displayed improved stability toward oxygen reduction [50]. This finding clearly indicates that the selective surface modification on vulnerable sites is a promising method to provide improved stability.

This concept was used by Lee et al. who reported an improved durability of octahedral PtNi NPs for oxygen reduction by using a halide treatment [51 $]$. In particular, the $\mathrm{Br}$ treated samples displayed a remarkable low mass activity decrease of about $15 \%$ in comparison with the $53 \%$ obtained with the bare PtNi octahedral NPs during the durability tests. The improved stability was attributed to the fact that the $\mathrm{Br}$ is strongly adsorbed on $\mathrm{Ni}$ preventing its leaching out during the electrochemical cycling thus preserving the nanoparticle shape and atomic composition and, consequently, the high activity, figure 3 .

Also, the incorporation of certain adatoms at the surface of SNPs can also provide improved stabilities in terms of lower deactivation activities. For instance, $\mathrm{Sb}$ and $\mathrm{Pb}$ decorated octahedral Pt NPs showed not only high activities towards formic acid electrooxidation but also low deactivation rates which is of outstanding importance for practical applications [32,34]. 


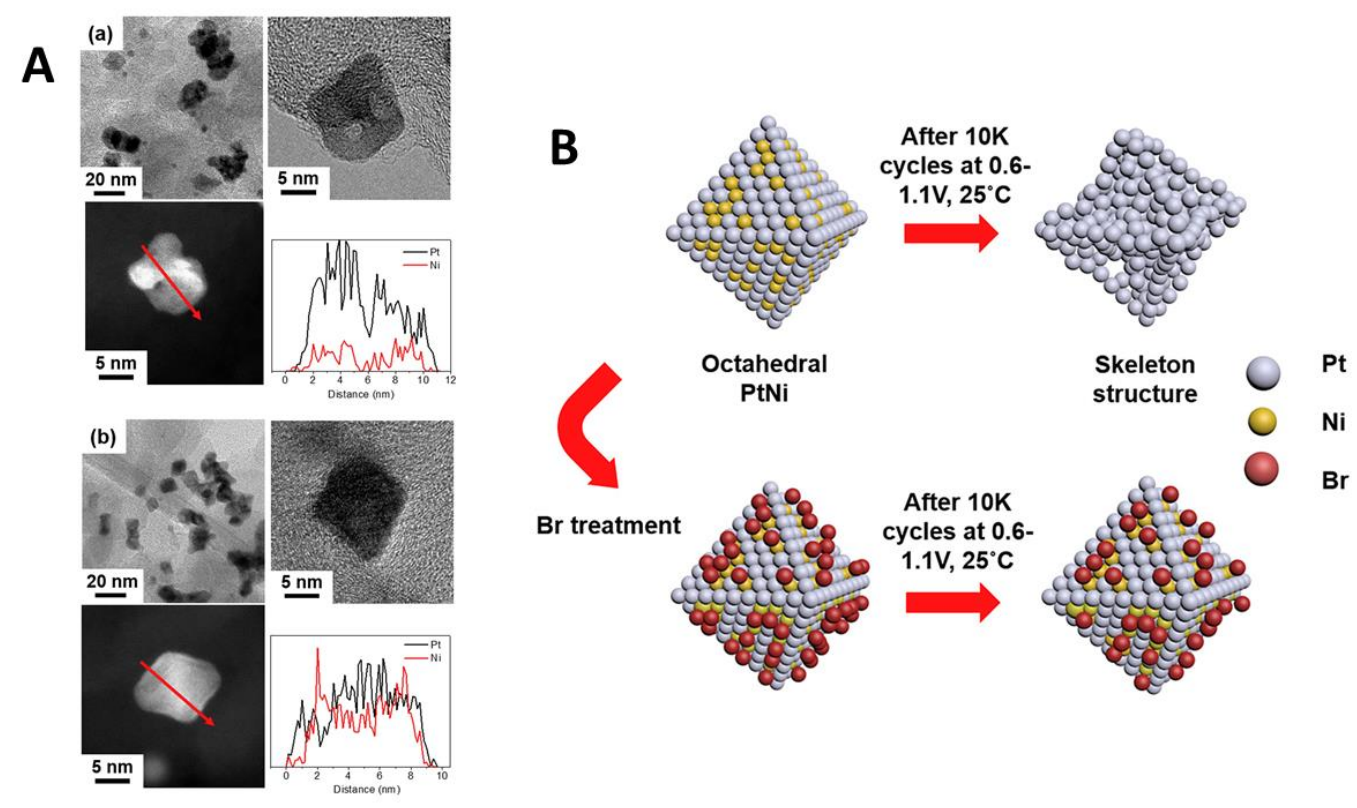

Figure 3. A) TEM, HR-TEM, HAADF-STEM images, and Pt and Ni elemental distribution along the red arrow in the STEM image of (a) as-prepared PtNi nanoparticles and (b) $\mathrm{Br}$ treated PtNi nanoparticles after ADT for 10,000 cycles. B) Schematic representation of the effect of the presence of $\mathrm{Br}$ on the stability of the octahedral PtNi NPs. Reprinted from ref [51]. Copyright (2016), with permission from Elsevier.

\section{Modified electrocatalytic selectivity}

The modification of the surface of SNPs with a foreign metal can also provide interesting opportunities to modify and control the selectivity of some reactions of interest including $\mathrm{CO}_{2}$ reduction and glycerol electrooxidation, figure 4 .

Sun and co-workers studied the electrochemical reduction $\mathrm{CO}_{2}$ on $\mathrm{Cu}$ modified $\mathrm{THH}$ and $\{111\}$ faceted Pd NPs [52]. Interestingly the selectivity towards methanol and ethanol was found to be dependent not only to the Cu coverage but also to the surface structure of the substrate. In brief, whereas the Cu1ML modified THH Pd NPs exhibited a high selectivity towards ethanol, the Cu0.8ML modified THH Pd NPs showed high selectivity for methanol. For $\mathrm{Cu}$ coverages higher than $1 \mathrm{ML}$ (Cu1.2ML modified THH Pd NPs) the activity towards methanol and ethanol decreased significantly and the selectivities were similar and comparable to that obtained with a polycrystalline $\mathrm{Cu}$ electrode. Interestingly, on Cu1ML modified THH Pd NPs the faradic efficiency towards ethanol was about $20 \%$ which is much higher than that obtained on Cu1ML modified (111)-faceted Pd nanoparticles (about 6\%) thus pointing out the effect of the surface structure of the substrate. 
Coutanceau and co-worker observed that the reaction pathway of glycerol oxidation in alkaline media can be modified when the surface of shape-controlled Pd NPs is decorated with $\mathrm{Bi}$ adatoms $[42,43]$. They found that unmodified shaped Pd NPs (nanocubes, nanooctaedrons and nanospheres) produce mainly glyceraldehyde and glycerate at low potentials with similar selectivity. At higher potentials more oxidized $\mathrm{C} 3, \mathrm{C} 2$ and $\mathrm{C} 1$ products were observed. However, in presence of $\mathrm{Bi}$, the selectivity of the reaction was found to be also dependent of the Bi coverage. Thus, for intermediate $\mathrm{Bi}$ coverages, the formation of dihydroxyacetone was observed with the decorated samples. In this regard, Koper and co-workers have recently reported the use of $\mathrm{Bi}$ modified $\left(\theta_{\mathrm{Bi}}\right.$ about 0.15 ) Pt single crystals toward the oxidation of glycerol in acidic solution [53]. They found that $\mathrm{Bi}$ decorated $\mathrm{Pt}(111)$ electrodes improved both the activity and the selectivity towards dihydroxyacetone. However, on $\mathrm{Bi}$ decorated $\mathrm{Pt}(100)$ electrodes the activity clearly decreased and the selectivity remained similar to the bare electrode (glyceraldehyde). These findings strongly suggest the use of $\mathrm{Bi}$ decorated shape-controlled Pt NPs toward the oxidation of glycerol in acidic solution, however, to the best or our knowledge, this is still unexplored. In this sense, it is worth noting that on adatom decorated ( $\mathrm{Bi}$ and $\mathrm{Sb}$ ) $\mathrm{Pt} / \mathrm{C}$ electrode, the selectivity of the electro-oxidation of glycerol towards dihydroxyacetone at low potentials was already found to be almost $100 \%$ [24,54]. Additionally, the bare surface structure of Pt was also shown to strongly determine the activity and selectivity of the electro-oxidation of glycerol [55].
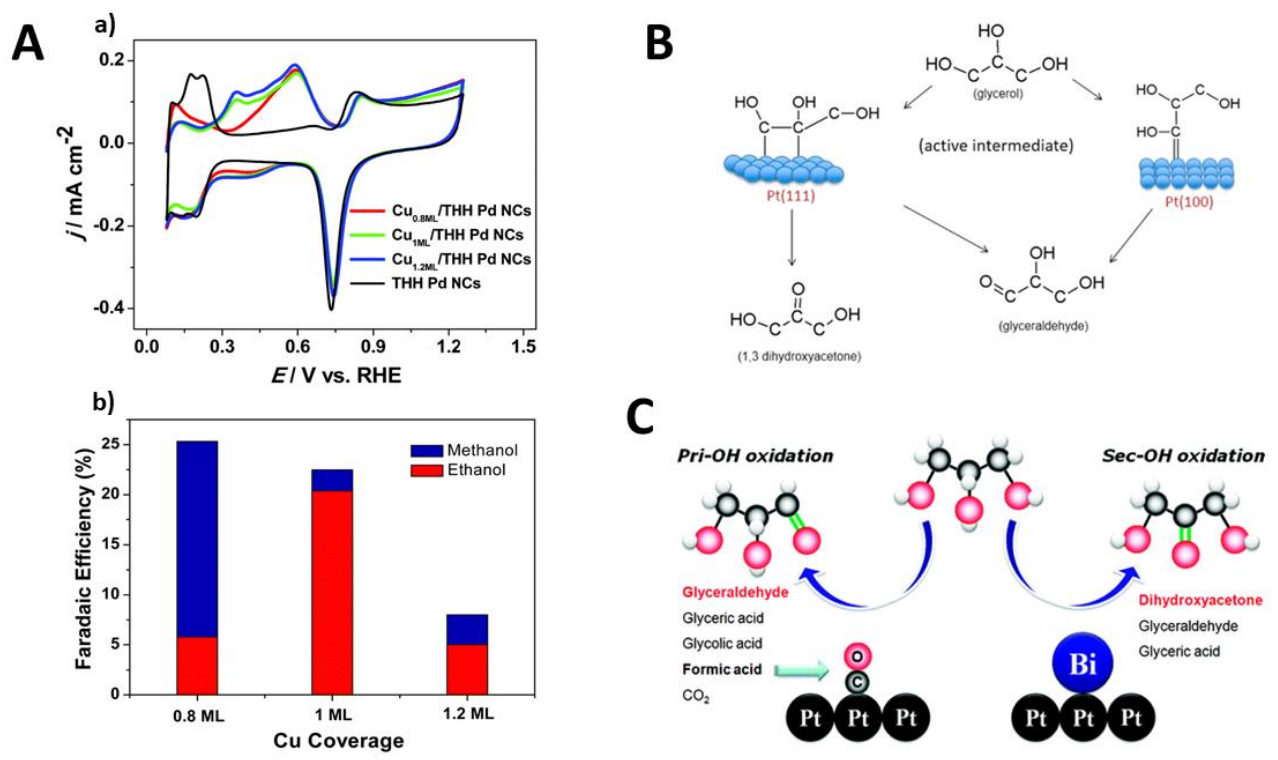

Figure 4. A) (a) Cu stripping curves of Cu-modified THH Pd NPs electrodes with different $\mathrm{Cu}$ coverages. Solution: $0.5 \mathrm{M} \mathrm{H}_{2} \mathrm{SO}_{4}$, scan rate: $100 \mathrm{mVs}^{-1}$. (b) Faradaic efficiency of methanol 
and ethanol on Cu-modified Pd THH NCs with different Cu coverages at $0.46 \mathrm{~V}$ vs. $\mathrm{RHE}$ in $\mathrm{CO}_{2}$ saturated $0.1 \mathrm{M} \mathrm{NaHCO}_{3}$ solution. Reproduced from ref [52] with permission of The Royal Society of Chemistry. B) Proposed glycerol oxidation mechanism on $\mathrm{Pt}(111)$ and $\mathrm{Pt}(100)$ electrodes in acidic solution. Reprinted with permission from ref [55]. Copyright (2016) American Chemical Society. C) Schematic diagram of the selective oxidation of glycerol in presence and absence of $\mathrm{Bi}$ adatoms. Reprinted with permission from ref [54]. Copyright (2012) American Chemical Society.

\section{Concluding remarks}

Adatom decorated SNPs are promising electrocatalysts for relevant energy conversion reactions. This short review summarizes some of the most interesting contributions. The existing literature point out that activity, stability and selectivity are susceptible to be enhanced using these advanced electrocatalysts. However, there are still some important aspects requiring future efforts including:

- New experimental strategies for a more selective decoration of the surface. For instance, Feliu et al. showed that it is possible to selectively decorate the surface of octahedral Pt NPs without blocking the $\{111\}$ terrace domains and studied their electrocatalytic properties [29].

- The structure of the 2D layer and/or the positions of the adatoms, as well as, the oxidation state and compounds that they form at different potentials is poorly understood. In situ, STM and synchrotron-based techniques can contribute to answer some of these questions [56,57].

- Systematic long-term stability measurements are still required to better evaluate the stability of the adatom modified electrocatalysts under different working conditions.

- Selectivity issues still need more systematic studies.

- Studies using practical electrochemical devices (fuel cell, electrolizer or filter press type reactors) are essentially missing.

\section{References and recommended reading}

Papers of particular interest, published within the period of review, have been highlighted as:

- paper of special interest

$\bullet \bullet$ paper of outstanding interest 


\section{Acknowledgments}

J.S-G and P.S.F. acknowledges financial support from FAPESP (Process numbers 2017/09780-0 and 2016/01365-0). J.S-G. also acknowledges financial support from VITC (Vicerrectorado de Investigación y Transferencia de Conocimiento) of the University of Alicante (UATALENTO16-02). M.B.C.S acknowledges CAPES for his fellowship.

\section{References}

[1] F.J. Vidal-Iglesias, J. Solla-Gullón, P. Rodríguez, E. Herrero, V. Montiel, J.M. Feliu, A. Aldaz, Shape-dependent electrocatalysis: ammonia oxidation on platinum nanoparticles with preferential (100) surfaces, Electrochem. Commun. 6 (10) (2004) 1080-1084. https://doi.org/10.1016/j.elecom.2004.08.010.

-. This is the first contribution on shape-controlled metal nanoparticles in Electrocatalysis.

[2] M.T.M. Koper, Structure sensitivity and nanoscale effects in electrocatalysis, Nanoscale 3 (2011) 2054-2073. https://doi.org/10.1039/CONR00857E.

[3] J. Solla-Gullón, F.J. Vidal-Iglesias, J.M. Feliu, Shape dependent electrocatalysis, Annu. Rep. Prog. Chem., Sect C: Phys. Chem. 107 (2011) 263-297. https://doi.org/10.1039/C1PC90010B.

[4] B. Wu, N. Zheng, Surface and interface control of noble metal nanocrystals for catalytic and electrocatalytic applications. Nano Today 8 (2) (2013) 168-197. http://dx.doi.org/10.1016/j.nantod.2013.02.006.

[5] H. Lee, Utilization of shape-controlled nanoparticles as catalysts with enhanced activity and selectivity, RSC Adv. 4 (2014) 41017-41027. http://dx.doi.org/10.1039/C4RA05958A.

[6] Y. Kang, P. Yang, N. M. Markovic, V. R. Stamenkovic, Shaping electrocatalysis through tailored nanomaterials, Nano Today 11 (4) (2016) 587-600. https://doi.org/10.1016/j.nantod.2016.08.008.

[7] J.W. Hong, Y. Kim, Y. Kwon, S. W. Han, Noble Metal Nanocrystals with Controlled Facets for Electrocatalysis, Chem. Asian J. 11 (2016) 2224-2239. https://doi.org/10.1002/asia.201600462. 
[8] F.J. Vidal-Iglesias, J. Solla-Gullón, J.M. Feliu, Recent advances in the use of shapecontrolled metal nanoparticles in electrocatalysis, in: I.K. Ozoemena, S. Chen (Eds.), Nanomaterials for Fuel Cell Catalysis, Springer International Publishing Switzerland, Cham, 2016, pp. 31-92. https://doi.org/10.1007/978-3-319-29930-3_2.

[9] X. Liu, W. Li, S. Zou, Electrocatalysis of Facet-controlled Noble Metal Nanomaterials for Low-temperature Fuel Cells, in: T. Maiyalagan, V. S. Saji (Eds.), Electrocatalysts for Low Temperature Fuel Cells: Fundamentals and Recent Trends, Wiley-VCH Verlag GmbH \& Co. KGaA, Weinheim, 2017, pp. 373-400. https://doi.org/10.1002/9783527803873.ch12.

[10] P. Strasser, M. Gliech, S. Kuehl, T. Moeller. Electrochemical processes on solid shaped nanoparticles with defined facets, Chem. Soc. Rev. (2018) Advance Article. https://doi.org/10.1039/C7CS00759K.

[11] M.A. Montiel, F.J. Vidal-Iglesias, V. Montiel, J. Solla-Gullón, Electrocatalysis on shape-controlled metal nanoparticles: Progress in surface cleaning methodologies, $\begin{array}{llllll}\text { Current } & \text { Opinion in } & \text { Electrochemistry } & 1 & \text { (2017) }\end{array}$ https://doi.org/10.1016/j.coelec.2016.12.007.

- This review summarizes the most relevant advances about surface cleaning procedures applied to shape-controlled metal nanoparticles for electrocatalytic purposes.

[12] A. Chen, P. Holt-Hindle, Platinum-Based Nanostructured Materials: Synthesis, Properties, and Applications, Chem. Rev. 110 (6) (2010) 3767-3804. https://doi.org/ $10.1021 /$ cr9003902.

[13] N. Jung, D. Y. Chungb, J. Ryu, S. J. Yoo, Y.E. Sung, Pt-based nanoarchitecture and catalyst design for fuel cell applications, Nano Today 9 (4) (2014) 433-456. https://doi.org/10.1016/j.nantod.2014.06.006.

[14] M. B. Gawande, A. Goswami, T. Asefa, H. Guo, A. V. Biradar, DL. Peng, R. Zboril, R. S. Varma, Core-shell nanoparticles: synthesis and applications in catalysis and electrocatalysis, Chem. Soc. Rev. $44 \quad$ (21) (2015) 7540-7590. https://doi.org/10.1039/C5CS00343A.

[15] J. Wang, B. Li, T. Yersak, D. Yang, Q. Xiao, J. Zhang, C. Zhang, Recent advances in Pt-based octahedral nanocrystals as high performance fuel cell catalysts, J. Mater. Chem. A, 4 (30) (2016) 11559-11581. https://doi.org/10.1039/C6TA02748B. 
[16] K. D. Gilroy, A. Ruditskiy, HC. Peng, D. Qin, Y. Xia, Bimetallic Nanocrystals: Syntheses, Properties, and Applications, Chem. Rev. 116 (18) (2016) 10414-10472. https://doi.org/10.1021/acs.chemrev.6b00211.

[17] T. Sheng, YF. Xu, YX. Jiang, L. Huang, N. Tian, ZY. Zhou, I. Broadwell, SG. Sun, Structure Design and Performance Tuning of Nanomaterials for Electrochemical Energy Conversion and Storage, Acc. Chem. Res. 49 (11) (2016) 2569-2577. https://doi.org/10.1021/acs.accounts.6b00485.

[18] A. M. El-Toni, M. A. Habila, J. P. Labis, Z. A. ALOthman, M. Alhoshan, A. A. Elzatahryf, F. Zhang, Design, synthesis and applications of core-shell, hollow core, and nanorattle multifunctional nanostructures, Nanoscale 8 (5) (2016) 2510-2531. https://doi.org/10.1039/C5NR07004J.

[19] J. Lai, S. Guo, Design of Ultrathin Pt-Based Multimetallic Nanostructures for Efficient Oxygen Reduction Electrocatalysis, Small 13 (48) (2017) 1702156. https://doi.org/10.1002/smll.201702156.

[20] M. Luo, S. Guo, Strain-controlled electrocatalysis on multimetallic nanomaterials, Nat. Rev. Mater. 2 (2017) 17059. https://doi.org/10.1038/natrevmats.2017.59.

[21] M. Watanabe, M. Horiuchi, S. Motoo, Electrocatalysis by ad-atoms: Part XXIII. Design of platinum ad-electrodes for formic acid fuel cells with ad-atoms of the IVth and the Vth groups, J. Electroanal. Chem. 250 (1) (1988) 117-125. https://doi.org/10.1016/0022-0728(88)80197-9.

[22] S.A. Campbell, R. Parsons, Effect of $\mathrm{Bi}$ and $\mathrm{Sn}$ adatoms on formic acid and methanol oxidation at well defined platinum surfaces, J. Chem. Soc., Faraday Trans. 88 (6) (1992) 833-841. https://doi.org/10.1039/FT9928800833.

[23] A. Boronat-González, E. Herrero, J. M. Feliu, Fundamental aspects of $\mathrm{HCOOH}$ oxidation at platinum single crystal surfaces with basal orientations and modified by irreversibly adsorbed adatoms, J. Solid State Electrochem. 18 (5) (2014) 1181-1193. https://doi.org/10.1007/s10008-013-2209-x.

[24] Y. Kwon, T. J. P. Hersbach, M. T. M. Koper, Electro-Oxidation of Glycerol on Platinum Modified by Adatoms: Activity and Selectivity Effects, Top. Catal. 57 (2014) 1272-1276. https://doi.org/10.1007/s11244-014-0292-6.

[25] M. C. Figueiredo, O. Sorsa, N. Doan, E. Pohjalainen, H. Hildebrand, P. Schmuki, B. P. Wilson, T. Kallio, Direct alcohol fuel cells: Increasing platinum performance by 
modification with sp-group metals, J. of Power Sources 275 (2015) 341-350. https://doi.org/10.1016/j.jpowsour.2014.11.034.

[26] G. L. Caneppele, T. S. Almeida, C. R. Zanata, E. Teixeira-Neto, P. S. Fernández, G. A. Camara, C. A. Martins, Exponential improving in the activity of $\mathrm{Pt} / \mathrm{C}$ nanoparticles towards glycerol electrooxidation by $\mathrm{Sb}$ ad-atoms deposition, Appl. Catal. B: Environm. 200 (2017) 114-120. https://doi.org/10.1016/j.apcatb.2016.06.072.

[27] A. Boronat-González, E. Herrero, J. M. Feliu, Heterogeneous electrocatalysis of formic acid oxidation on platinum single crystal electrodes, Current Opinion in Electrochemistry 4 (1) (2017) 26-31. https://doi.org/10.1016/j.coelec.2017.06.003.

[28] A. López-Cudero, F. J. Vidal-Iglesias, J. Solla-Gullón, E. Herrero, A. Aldaz, J. M. Feliu, Formic acid electrooxidation on Bi-modified polyoriented and preferential (111) Pt nanoparticles, Phys. Chem. Chem. Phys. 11 (2) (2009) 416-424. https://doi.org/10.1039/B814072C.

-• This is the first case of adatom decorated shape-controlled metal nanoparticles for electrocatalytic energy conversion reactions.

[29] QS. Chen, F.J. Vidal-Iglesias, J. Solla-Gullón, SG. Sun, J.M. Feliu, Role of surface defect sites: from Pt model surfaces to shape-controlled nanoparticles, Chem. Sci. 3 (1) (2012) 136-147. https://doi.org/10.1039/C1SC00503K.

[30] F. J. Vidal-Iglesias, J. Solla-Gullón, E. Herrero, A. Aldaz, J. M. Feliu, Pd Adatom Decorated (100) Preferentially Oriented Pt Nanoparticles for Formic Acid Electrooxidation. Angew. Chem. Int. Ed. 49 (39) (2010) 6998 -7001. https://doi.org/10.1002/anie.201002501.

[31] F. J. Vidal-Iglesias, A. López-Cudero, J. Solla-Gullón, A. Aldaz, J. M. Feliu, PdModified Shape-Controlled Pt Nanoparticles Towards Formic Acid Electrooxidation, Electrocatal. 3 (2012) 313-323. https://doi.org/10.1007/s12678-012-0094-1.

[32] F. J. Vidal-Iglesias, A. López-Cudero, J. Solla-Gullón, J. M. Feliu, Towards More Active and Stable Electrocatalysts for Formic Acid Electrooxidation: AntimonyDecorated Octahedral Platinum Nanoparticles. Angew. Chem. Int. Ed. 52 (3) (2013) 964 -967. https://doi.org/10.1002/anie.201207517.

[33] C. Busó-Rogero, J. V. Perales-Rondón, M.J. S. Farias, F. J. Vidal-Iglesias, J. Solla-Gullón, E. Herrero, J. M. Feliu, Formic acid electrooxidation on thalliumdecorated shape-controlled platinum nanoparticles: an improvement in electrocatalytic 
activity, Phys. Chem. Chem. Phys. 16 (27) (2014) 13616-13624. https://doi.org/10.1039/C4CP00304G.

[34] J. V. Perales-Rondón, J. Solla-Gullón, E. Herrero, C. M. Sánchez-Sánchez, Enhanced catalytic activity and stability for the electrooxidation of formic acid on lead modified shape controlled platinum nanoparticles, Appl. Catal. B: Environm. 201 (2017) 48-57. https://doi.org/10.1016/j.apcatb.2016.08.011.

[35] QS. Chen, ZY. Zhou, F. J. Vidal-Iglesias, J. Solla-Gullón, J. M. Feliu, SG. Sun, Significantly Enhancing Catalytic Activity of Tetrahexahedral Pt Nanocrystals by Bi Adatom Decoration. J. Am. Chem. Soc. 133 (33) (2011) https://doi.org/12930-12933. 10.1021/ja2042029.

- This paper shows, for the first time, the use of adatom surface decoration with highindex Pt NPs and their electrocatalytic properties toward formic acid electrooxidation.

[36] HX. Liu, N. Tian, M. P. Brandon, J. Pei, ZC. Huangfu, C. Zhan, ZY. Zhou, C. Hardacre, WF. Lin, SG. Sun, Enhancing the activity and tuning the mechanism of formic acid oxidation at tetrahexahedral Pt nanocrystals by Au decoration, Phys. Chem. Chem. Phys. 14 (47) (2012) 16415-16423. https://doi.org/10.1039/C2CP42930F.

[37] S. Yang, H. Lee, Atomically Dispersed Platinum on Gold Nano-Octahedra with High Catalytic Activity on Formic Acid Oxidation, ACS Catal. 3 (3) (2013) 437-443. https://doi.org/10.1021/cs300809j.

[38] HX. Liu, N. Tian, M. P. Brandon, ZY. Zhou, JL. Lin, C. Hardacre, WF. Lin, SG. Sun, Tetrahexahedral Pt Nanocrystal Catalysts Decorated with Ru Adatoms and Their Enhanced Activity in Methanol Electrooxidation. ACS Catal. 2 (5) (2012) 708-715. https://doi.org/10.1021/cs200686a.

[39] P. Wang, X. Lin, B. Yang, JM. Jin, C. Hardacre, NF. Yu, SG. Sun, WF. Lin, Activity Enhancement of Tetrahexahedral Pd Nanocrystals by Bi Decoration towards Ethanol Electrooxidation in Alkaline Media, Electrochimica Acta 162 (2015) 290-299. https://doi.org/10.1016/j.electacta.2015.02.177.

[40] C. Busó-Rogero, J. Solla-Gullón, F. J. Vidal-Iglesias, E. Herrero, J. M. Feliu, Adatom modified shape-controlled platinum nanoparticles towards ethanol oxidation, $\begin{array}{llll}\text { Electrochimica } & \text { Acta } & 196 & \text { (2016) }\end{array}$ https://doi.org/10.1016/j.electacta.2016.02.171.

[41] H. Wang, B. Jiang, TT. Zhao, K. Jiang, YY. Yang, J. Zhang, Z. Xie, WB. Cai, Electrocatalysis of Ethylene Glycol Oxidation on Bare and Bi- Modified Pd Concave 
Nanocubes in Alkaline Solution: An Interfacial Infrared Spectroscopic Investigation, ACS Catal. 7 (3) (2017) 2033-2041. https://doi.org/10.1021/acscatal.6b03108.

[42] A. Zalineeva, S. Baranton, C. Coutanceau, Bi-modified palladium nanocubes for glycerol electrooxidation, Electrochem. Commun. $34 \quad$ (2013) 335-338. https://doi.org/10.1016/j.elecom.2013.07.022.

[43] A. Zalineeva, S. Baranton, C. Coutanceau, How do Bi-modified palladium nanoparticles work towards glycerol electrooxidation? An in situ FTIR study, $\begin{array}{llll}\text { Electrochimica } & \text { Acta } & 176 & \text { (2015) }\end{array}$ https://doi.org/10.1016/j.electacta.2015.07.073.

- This paper clearly illustrates how selectivity can be modified by using adatom decorated shape-controlled metal nanoparticles. In particular, this contribution shows how the reaction pathway of glycerol electrooxidation is affected through the use of $\mathrm{Bi}$ decorated shaped Pd (nanocubes and nanooctahedrons) nanoparticles.

[44] X. Huang, Z. Zhao, L. Cao, Y. Chen, E. Zhu, Z. Lin, M. Li, A. Yan, A. Zettl, Y. M. Wang, X. Duan, T. Mueller, Y. Huang, High-performance transition metal-doped $\mathrm{Pt}_{3} \mathrm{Ni}$ octahedra for oxygen reduction reaction, Science 348 (6240) (2015) 1230-1234. https://doi.org/10.1126/science.aaa8765.

[45] V. Beermann, M. Gocyla, E. Wilinger, S. Rudi, M. Heggen, R. E. Dunin-Barkowski, MG. Wilinger, P. Strasser, Rh-Doped Pt-Ni Octahedral Nanoparticles: Understanding the Correlation between Elemental Distribution, Oxygen Reduction Reaction, and

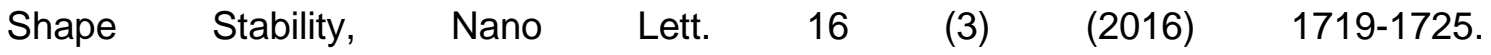
https://doi.org/10.1021/acs.nanolett.5b04636.

[46] H. Lv, D. Li, D. Strmcnik, A. P. Paulikas, N. M. Markovic, V. R. Stamenkovic, Recent advances in the design of tailored nanomaterials for efficient oxygen reduction $\begin{array}{llll}\text { reaction, Nano } \quad \text { Energy } & 29 & \text { (2016) }\end{array}$ https://doi.org/10.1016/j.nanoen.2016.04.008.

[47] V. Colić, A. S. Bandarenka, Pt Alloy Electrocatalysts for the Oxygen Reduction Reaction: From Model Surfaces to Nanostructured Systems, ACS Catal. 6 (8) (2016) 5378-5385. https://doi.org/10.1021/acscatal.6b00997.

[48] M. Shao, Q. Chang, JP. Dodelet, R. Chenitz, Recent Advances in Electrocatalysts for Oxygen Reduction Reaction, Chem. Rev. 116 (6) (2016) 3594-3657. https://doi.org/10.1021/acs.chemrev.5b00462. 
[49] C. Zhang, X. Shen, Y. Pan, Z. Peng. A review of Pt-based electrocatalysts for oxygen reduction reaction, Frontiers in Energy 11 (3) (2017) 268-285. https://doi.org/10.1007/s11708-017-0466-6.

[50] K. Kodama, R. Jinnouchi, N. Takahashi, H. Murata, Y. Morimoto, Activities and Stabilities of Au-Modified Stepped-Pt Single-Crystal Electrodes as Model Cathode Catalysts in Polymer Electrolyte Fuel Cells, 138 (12) (2016) https://doi.org/4194-4200. $10.1021 /$ jacs.6b00359.

[51] J. Choi, Y. Lee, J. Kim, H. Lee, Enhancing stability of octahedral PtNi nanoparticles for oxygen reduction reaction by halide treatment, J. of Power Sources 307 (2016) 883-890. https://doi.org/10.1016/j.jpowsour.2016.01.063.

- This paper shows how effective surface decoration is to enhance the long-term stability of PtNi octahedral nanoparticles for oxygen reduction reduction.

[52] FY. Zhang, T. Sheng, N. Tian, L. Liu, C. Xiao, BA. Lu, BB. Xu, ZY. Zhou, SG. Sun, $\mathrm{Cu}$ overlayers on tetrahexahedral $\mathrm{Pd}$ nanocrystals with high-index facets for $\mathrm{CO}_{2}$ electroreduction to alcohols, Chem. Commun. 53 (57) (2017) https://doi.org/8085-8088. 10.1039/C7CC04140C.

[53] A. C. Garcia, Y. Y. Birdja, G. Tremiliosi-Filho, M. T.M. Koper, Glycerol electrooxidation on bismuth-modified platinum single crystals, J. of Catal. 346 (2017) 117124. https://doi.org/10.1016/j.jcat.2016.12.013.

[54] Y. Kwon, Y. Birdja, I. Spanos, P. Rodriguez, M. T. M. Koper, Highly Selective Electro-Oxidation of Glycerol to Dihydroxyacetone on Platinum in the Presence of Bismuth, ACS Catal. 2 (5) (2012) 759-764. https://doi.org/ 10.1021/cs200599g.

[55] A. C. Garcia, M. J. Kolb, C. van Nierop y Sanchez, J. Vos, Y. Y. Birdja, Y. Kwon, G. Tremiliosi-Filho, M. T. M. Koper, Strong Impact of Platinum Surface Structure on Primary and Secondary Alcohol Oxidation during Electro-Oxidation of Glycerol, ACS Catal. 6 (7) (2016) 4491-4500. https://doi.org/ 10.1021/acscatal.6b00709.

[56] K. Uosaki, In situ real-time monitoring of geometric, electronic, and molecular structures at solid/liquid interfaces, Jpn. J. Appl. Phys. 54 (2015) 030102. http://dx.doi.org/10.7567/JJAP.54.030102.

[57] YW. Choi, H. Mistry, B. R. Cuenya, New insights into working nanostructured electrocatalysts through operando spectroscopy and microscopy, Current Opinion in Electrochemistry 1 (2017) 95-103. https://doi.org/10.1016/j.coelec.2017.01.004. 